\title{
Does Oral Lycopene Reduce Benign Prostate Enlargement/Hyperplasia $(\mathrm{BPE} / \mathrm{BPH})$ ?
}

\author{
Hitendra RH Patel ${ }^{1 *}$, Walid Elbakbak², Amina Bouhelal ${ }^{3}$ and Stig Müller ${ }^{4}$ \\ ${ }^{1}$ Department of Urology, University Hospital North Norway, Tromso, Norway \\ ${ }^{2}$ Department of Urology, University Hospital North Norway, Tromso, Norway \\ ${ }^{3}$ Royal Free Hospital, University College of London, UK \\ ${ }^{4}$ Department of Urology, Akershus University Hospital, Institute of Clinical Medicine, University of Oslo, Norway
}

\begin{abstract}
Aims: Lycopene is a potent antioxidant found in 'Mediterranean diets' with evidence suggesting a beneficial effect on the prostate. Our objective was to critically appraise the current literature as to whether Lycopene has a beneficial
\end{abstract} effect on benign prostatic enlargement.

Methods: We searched PubMed electronic databases for articles published from 2000. The following key words were used: lycopene and prostate or prostate cancer or prostatitis or BPH or BOO or LUTS or LUTD or BPE, in vitro or in vivo, animal study.

Results: The literature search identified 91 articles for analysis, 24 in vitro, 9 in vivo, 43 clinical and 15 review articles. We analyzed the papers with regards to bioavailability of lycopene, laboratory findings and clinical results of lycopene supplementation.

Conclusions: Lycopene has beneficial effects on prostate and several mechanisms of action have been identified in laboratory and clinical studies. However, the most important issue regarding future trials with lycopene is bioavailability.

Keywords: Lycopene; Diet; Prostate; Prostate cancer; LUTS; Supplementation; Tomato; BPH

\section{Introduction}

Lycopene is an active carotenoid component of tomatoes giving them their familiar red colour. It is a potent antioxidant with a singletoxygen quenching ability twice that of $\beta$-carotene and ten times that of Vitamin E due to its structure. It is known to be a promising nutritional chemoprevention agent for prostate cancer [1]. However, during the 1990s the lycopene studies were based around lycopene products, which were considered to have poor or variable bioavailability, which led to inconsistencies in study outcomes [2]. Specifically, food based interventions involving consumption of large volumes of tomato products (e.g. juice or paste) or by the use of heterogeneous tomato extracts containing mixtures of carotenoids were unstandardized $[2,3]$. Clinical evidence for prostate health benefits of lycopene has been limited to patients with prostate cancer or high-grade prostatic intraepithelial neoplasia $[4,5]$. Epidemiological studies have established an association between tomato product intake, lycopene levels and prostate cancer risk reduction $[1,2]$ but larger intervention trials are needed to determine the effect size of lycopene supplementation [6]. However, in vitro and animal studies have revealed several mechanisms of action of lycopene in the prostate that may play a role in prostate cancer initiation, promotion and progression. Some of these may also play a role in benign prostate hyperplasia (BPH). BPH and clinically associated lower urinary tract symptoms/dysfunction (LUTS/D) is a common disease of elderly men affecting 50 to $90 \%$ of all men between 50 and 80 years of age. These men will be treated by a variety of medications with associated side effects such as loss of libido, sexual dysfunction, hypotension and others. There are no known serious side-effects of lycopene, hence lycopene supplementation seems favorable if efficacy on LUTS/D and/or BPH is proven. Nutritional supplements and botanicals are widely used for symptom relief in LUTS/D and some, either as single intervention or combination, have shown promising results. However, the evidence level of clinical studies still precludes guideline recommendation of their use [7]. Although human and animal studies point to beneficial effects on $\mathrm{BPH}$, the mechanism of action of many plant-derived agents are not yet fully understood [8]. A possible beneficial role of lycopene in patients diagnosed with benign prostate hyperplasia (BPH), has been studied in vitro [9-11] and by clinical randomized trials [12]. Several issues complicate the interpretation of the results. First, lycopene has been studied as single intervention or combined with other plantderived agents (e.g. serenoa repens) or vitamin E. Secondly, the dose of lycopene and mode of supplementation (tomato-derived food product or extract) varies across the studies. The latter has a significant effect on the bioavailability of lycopene that may consequently lead to different results. Thus, our aim was to assess the published evidence of the effect of lycopene on $\mathrm{BPH}$ and associated LUTS/D by performing a critical review of the literature.

\section{Methods}

We searched PubMed electronic databases for articles published from 2000. Four main categories of studies have been selected: in vitro studies, in vivo studies, clinical studies and review articles. The results were confirmed by the similar search through Google. For clinical studies and review articles we used the following key words for search: lycopene and prostate or prostate cancer or prostatitis or $\mathrm{BPH}$ or $\mathrm{BOO}$ or LUTS or LUTD or BPE. For in vitro and in vivo models we used key words like lycopene and prostate, in vitro or in vivo, animal study.

*Corresponding author: Hitendra RH Patel, Department of Urology, University Hospital North Norway, Tromso, Norway, Tel: +47 07766; E-mail: urology@hrhpatel.org

Received: January 11, 2016; Accepted: January 27, 2016; Published: February 01, 2016

Citation: Patel HRH, Elbakbak W, Bouhelal A, Müller S (2016) Does Oral Lycopene Reduce Benign Prostate Enlargement/Hyperplasia (BPE/BPH)? Oncol Cancer Case Rep 1: 108.

Copyright: @ 2016 Patel HRH, et al. This is an open-access article distributed under the terms of the Creative Commons Attribution License, which permits unrestricted use, distribution, and reproduction in any medium, provided the original author and source are credited. 
The final list of clinical studies was created considering several criteria available in an article, the level of lycopene in serum, information about the source of lycopene, protocol of a study and clear outcome results. For non-human studies any innovative studies adding value to the understanding of the mechanism of action of lycopene in prostate in vitro or in vivo models were included.

\section{Results}

The literature search identified 91 articles for analysis, 24 in vitro, 9 in vivo, 43 clinical and 15 review articles. Sixty-seven original articles addressed prostate cancer and the findings were included in the analysis when potentially applicable to $\mathrm{BPH}$. We analyzed the papers with regards to bioavailability of lycopene, laboratory findings (i.e. mechanisms of action) and clinical results of lycopene supplementation. The results of the literature search are shown in tables 1 and 2 for laboratory and clinical studies.

\section{Discussion}

\section{Bioavailability of lycopene}

A healthy diet is a common, general advice for patients with disease. Increasing the intake of vegetables has no side-effects and increases the intake of protective dietary factors like lycopene [13]. Dietary adherence to tomato product consumption increases plasma levels of lycopene [14]. In men in active surveillance for prostate cancer, a telephone-based dietary intervention (one serving of tomato product per day) increases lycopene levels [15]. Diet change towards a vegetable-rich diet can be challenging for men. Mindfulness training programs can be feasible to support a dietary change over time [16]. The absorption of lycopene is a complex issue involving release from the food microstructure matrix, dissolution into mixed micelles, intestinal uptake and incorporation into chylomicrons. Lycopene is distributed to e.g. prostatic tissue and the liver, where it is re-secreted into VLDL, which are progressively transformed into LDL. Increased intake of lycopene increases both plasma levels and lycopene content of prostate tissue $[17,18]$. The plasma half-life of lycopene is approximately 2 weeks [19]. The best food sources providing lycopene in a bioavailable form are tomatoderived food products, whereas lycopene from other sources such as fresh tomatoes and unheated tomato juice is poorly absorbed. The bioavailability of lycopene from tomato products is greatly enhanced after mechanical texture disruption and thermal processing. Such treatment increases the accessibility of the lycopene but also helps to disperse the liposoluble lycopene in the food matrix. In concentrated tomato extracts, the poorly soluble lycopene is predominantly crystallized and the crystalline form of carotenoids has been found to be one of the primary factors that reduce their bioavailability. However, if the particle size of lycopene is minimized, its bioavailability will be enhanced. Unprocessed tomatoes contain mostly all-trans lycopene isomer while lycopene found in prostate tissue predominantly is cis-isomers suggesting a better bioavailability for cis-lycopene [20]. Tangerine tomatoes contain more cis isomers. Interestingly, tomato products from tangerine tomatoes increase the uptake of both cis and trans lycopene [21]. Both tomato food products and lycopene extracts have been shown to increase plasma levels of lycopene. However, in a study using tomato-based juice as lycopene source, $80 \%$ of the subjects absorbed only $6 \mathrm{mg}$ of lycopene, even when given doses of up to 120 $\mathrm{mg}$ of lycopene [22]. Lycopene supplementation in tablet form may be more attractive for some since a regular intake of tomato-paste or sauce is not necessary. Richelle et al., tested the bioavailability of lactolycopene, crystalline lycopene embedded in a whey protein matrix, in a randomized fashion compared to tomato paste and placebo. The formulation of lactolycopene decreases the crystal size of lycopene significantly, resulting in a probable better resorption. After 3 weeks of supplementation with $25 \mathrm{mg}$ of lycopene, administered as either tomato paste or lactolycopene in 36 healthy subjects, lycopene levels increased equally in both groups (2.6 and 2.7 times, respectively). There was no increase in the placebo group [20]. Thus, lycopene supplementation is possible without the need for consumption of large quantities of tomato paste.

\section{Laboratory findings}

Several mechanisms of action of lycopene in prostate cells have been described. Lycopene is a potent antioxidant and has antiproliferative, pro-apoptotic properties in the prostate. Several animal studies, mostly using transgenic rat models have documented reduced tumour growth [23-25] and altered gene expression counteracting carcinogenesis [24-27]. Lycopene affects the insulin-like growth factor system which has a proposed key role in carcinogenesis in the prostate. An inverse association between lycopene intake and IGF-1 levels has been observed in men [28] suggesting a link between lycopene deficiency and prostate cancer. Lycopene also influences the insuline-like growth factor system in normal prostate cells. In cultured prostate cancer cell lines and normal prostate epithelium cells, lycopene inhibits the insulin-like growth factor 1 (IGF-1) stimulated cell growth by reducing dihydrotestosterone stimulated IGF-1 production [29]. However, in a clinical study of lycopene supplementation in 97 men with low burden prostate cancer under active surveillance, only a third of the patients randomized to 3 months lycopene supplementation had a twofold decrease of IGF-1 gene expression in prostatic tissue compared to placebo, resulting in an overall not significant decrease of IGF-1 gene expression by lycopene [30]. This result may be due to the size of the study or, potentially, the effect of lycopene on IGF-1 production is diluted form bench to bedside. In normal rats, lycopene supplementation reduces IGF-1 expression, local prostatic androgen signaling and inflammatory signals without affecting prostate growth [11,31]. Anyhow, lycopene appears to have multiple effects on the IGFsystem. In a study by Talvas et al., sera from healthy men supplemented with lycopene upregulated IGF1binding protein in prostate cancer cell cultures while the expression of IGF-1 was unchanged [32]. Although there is little data on lycopene's effect on the IGF-system in BPH, this mechanism of action may counteract prostate growth in BPH. Qiu et al. have investigated proteomics in normal prostate epithelium cells exposed to lycopene vs. placebo and found that lycopene reduces oxidative stress in the cells, upregulates proteins that can promote apoptosis and down-regulates several proteins that are involved in anti-apoptosis [33]. In a study on cell viability and apoptosis in prostate cancer cell cultures, lycopene induces cell cycle arrest and apoptosis compared to placebo. However, no such effect was observed in BPH cells [34]. The promotion of cell cycle arrest and apoptosis by lycopene in prostate cancer cells is supported by another similar study [35]. Some of the potential health benefits of lycopene have been attributed to the potent antioxidant properties. As lycopene is accumulated in prostate tissue, an antioxidant effect should be detectable in the prostate. For instance, the receptor for advanced glycation end products (RAGE) and the soluble form (sRAGE) is, among many organs, expressed in prostate tissue. Activation of RAGE induces oxidative stress. Pathological conditions such as diabetes, vascular disease and cancer are associated with increased expression of sRAGE. In a study in healthy volunteers and normospermic male partners from infertile relationships, lycopene supplementation reduced sRAGE levels in seminal plasma both groups but not in blood plasma [36]. This suggests a specific antioxidative effect of lycopene in the prostate. However, in a randomized controlled 
trial in African American healthy men aged 50-83 years receiving 30 mg lycopene or placebo, lycopene levels in prostate tissue increased significantly but there was no evidence of oxidative stress reduction. In detail, products of DNA oxidation and lipid peroxidation were not altered by increased lycopene levels [17]. Thus, increased levels of lycopene in the prostate do not prevent products of oxidative stress but there is evidence of oxidative stress reduction by lycopene supplementation, depending on the markers measured. Clearly, there is a need for further research to understand mechanisms of action of lycopene in reducing oxidative stress and their clinical significance.

\section{Clinical studies}

Over the past 15 years, the question whether lycopene supplementation is associated with prostate cancer risk reduction has been investigated in major epidemiological trials. The largest trials, as for instance the Prostate, Lung, Colorectal, and Ovarian Cancer Screening Trial and the Prostate Cancer Prevention Trial, have not been able to document a certain association between higher levels of lycopene and prostate cancer risk reduction [37-39]. However, some epidemiological studies have shown a risk reduction with increased tomato product intake $[1,2]$. A Cochrane database systematic review of randomized trials concluded that there is still insufficient evidence to support or refute lycopene supplementation for prostate cancer risk reduction [40]. In clinical studies, a prostate-specific antigen (PSA) lowering effect of lycopene has been observed both in men with high risk for prostate cancer [41], known prostate cancer[42,43] and BPH [44]. A decrease in PSA during lycopene supplementation may be due its antiinflammatory and anti-proliferative effects seen in laboratory studies. An accumulation of lycopene in the prostate is already evident after 3 weeks of tomato product enriched diet e.g. in men consuming tomatosauce daily 3 weeks before radical prostatectomy[45]. However, do the potential beneficial effects of lycopene translate to clinical improvement of LUTS/D? There are few randomized, controlled trials investigating clinical effects of lycopene. In the PROCOMB trial, Profluss ${ }^{\oplus}$ was tested in men with symptomatic LUTS/D. Profluss ${ }^{\circledR}$ contains a combination of serenoa repens (berries of the American dwarf palm), selenium and lycopene. The rationale for this combination arises from a BPH rat model where the ingredients were given solely and in combination and the pro-apoptotic effects were measured. The combination of the three ingredients had the most pronounced effect [46]. Patients were randomized to receive Profluss ${ }^{\oplus}$, Tamsulosin or both for one year. Both interventions improved International Prostate Symptom Score (IPSS) significantly, especially in combination [47]. Profluss ${ }^{\bullet}$ also appears to have anti-inflammatory effects, evident from less inflammation in histology after treatment [48] and clinical improvement of chronic pelvic pain syndrome [49]. Schwarz et al., investigated lycopene as single intervention in men with BPH. Patients were randomized to 15 $\mathrm{mg}$ lycopene vs placebo. PSA was significantly reduced in the lycopene group and prostate volume was unchanged after 6 months. In the placebo group, a $24 \%$ increase of prostate volume was observed. Thus, lycopene can potentially inhibit disease progression in BPH. Interestingly, IPSS scores improved in both groups with a slightly greater improvement in the lycopene group. This may be due to rather low IPSS scores at inclusion and clinical improvement not being a primary endpoint.

\section{Conclusions}

Lycopene has beneficial effects on prostate. Preventive effects on prostate cancer are still a matter of debate. Many laboratory findings are theoretically of importance in disease progression in BPH and LUTS/D. Larger clinical trials are needed to explore the clinical benefit. However, the most important issue regarding future trials with lycopene is bioavailability. To date, most studies have been undersized or have used unstandardized methods of lycopene supplementation as a variety of tomato products. The best available mode of lycopene supplementation in clinical trials appears to be lactolycopene. There is documentation on good bioavailability [20], plasma levels can be monitored by non-invasive spectroscopy [50] and it has already been utilized in clinical trials. In a recent randomized, controlled trial in patients with cardiovascular disease and healthy volunteers, lycopene supplementation with lactolycopene restored endothelial dysfunction [51]. This points out potential health benefits of lycopene that are yet unexplored.

\section{Author contribution}

$\mathrm{WE}$ and $\mathrm{AB}$ searched the medical literature and extracted the data used in the study. HP and SM analysed the data extraction, confirmed the searches were valid. SM and HP produced the initial manuscript and final manuscript. HP is guarantor for the study and the senior author.

\section{Conflict of interest}

HP received an educational grant from Camnutra (Cambridge, UK) to undertake the study.

\section{References}

1. Giovannucci E (2005) Tomato products, lycopene, and prostate cancer: a review of the epidemiological literature. J Nutr 135: 2030S-1S.

2. Giovannucci E (2002) A review of epidemiologic studies of tomatoes, lycopene and prostate cancer. Exp Biol Med (Maywood) 227: 852-859.

3. Le Marchand L, Hankin JH, Kolonel LN, Wilkens LR (1991) Vegetable and fruit consumption in relation to prostate cancer risk in Hawaii: a reevaluation of the effect of dietary beta-carotene. Am J Epidemiol 133: 215-219.

4. Stacewicz-Sapuntzakis M, Bowen PE (2005) Role of lycopene and tomato products in prostate health. Biochim Biophys Acta 1740: 202-205.

5. Mohanty NK, Saxena S, Singh UP, Goyal NK, Arora RP (2005) Lycopene as a chemopreventive agent in the treatment of high-grade prostate intraepithelial neoplasia. Urol Oncol 23: 383-385.

6. Van Poppel H, Tombal B (2011) Chemoprevention of prostate cancer with nutrients and supplements. Cancer Manag Res 3: 91-100.

7. Madersbacher S, Berger I, Ponholzer A, Marszalek M (2008) Plant extracts: sense or nonsense? Curr Opin Urol 18: 16-20.

8. Azimi H (2012) A review of animal and human studies for management of benign prostatic hyperplasia with natural products: perspective of new pharmacological agents. Inflamm Allergy Drug Targets 11: 207221.

9. Kim HS, Bowen P, Chen L, Duncan C, Ghosh L, et al. (2003) Effects of tomato sauce consumption on apoptotic cell death in prostate benign hyperplasia and carcinoma. Nutr Cancer 47: 40-47.

10. Obermüller-Jevic UC, Olano-Martin E, Corbacho AM, Eiserich JP, van der Vliet A, et al. (2003) Lycopene inhibits the growth of normal human prostate epithelial cells in vitro. J Nutr 133: 3356-3360.

11. Herzog A, Siler U, Spitzer V, Seifert N, Denelavas A, et al. (2005) Lycopene reduced gene expression of steroid targets and inflammatory markers in normal rat prostate. FASEB J 19: 272-274

12. Schwarz S, Obermüller-Jevic UC, Hellmis E, Koch W, Jacobi G, et al. (2008) Lycopene inhibits disease progression in patients with benign prostate hyperplasia. J Nutr 138: 49-53.

13. Dewell A, Weidner G, Sumner MD, Chi CS, Ornish D (2008) A very-low-fat vegan diet increases intake of protective dietary factors and decreases intake of pathogenic dietary factors. J Am Diet Assoc 108: 347-356.

14. Park E, Stacewicz-Sapuntzakis M, Sharifi R, Wu Z, Freeman VL, et al. (2013) Diet adherence dynamics and physiological responses to a tomato product whole-food intervention in African-American men. Br J Nutr 109: 2219-2230. 
Citation: Patel HRH, Elbakbak W, Bouhelal A, Müller S (2016) Does Oral Lycopene Reduce Benign Prostate Enlargement/Hyperplasia (BPE/BPH)? Oncol Cancer Case Rep 1: 108.

15. Parsons JK, Newman VA, Mohler JL, Pierce JP, Flatt S, et al. (2008) Dietary modification in patients with prostate cancer on active surveillance: a randomized, multicentre feasibility study. BJU Int 101: 1227-1231.

16. Carmody JF, Olendzki BC, Merriam PA, Liu Q, Qiao Y, et al. (2012) A nove measure of dietary change in a prostate cancer dietary program incorporating mindfulness training. J Acad Nutr Diet 112: 1822-1827.

17. van Breemen RB, Sharifi R, Viana M, Pajkovic N, Zhu D, et al. (2011) Antioxidant effects of lycopene in African American men with prostate cancer or benign prostate hyperplasia: a randomized, controlled trial. Cancer Prev Res (Phila) 4: 711-718.

18. Barber NJ, Barber J (2002) Lycopene and prostate cancer. Prostate Cancer Prostatic Dis 5: 6-12.

19. Hadley CW, Miller EC, Schwartz SJ, Clinton SK (2002) Tomatoes, lycopene, and prostate cancer: progress and promise. Exp Biol Med (Maywood) 227: 869-880.

20. Richelle M, Bortlik K, Liardet S, Hager C, Lambelet P, et al. (2002) A food-based formulation provides lycopene with the same bioavailability to humans as that from tomato paste. J Nutr 132: 404-408.

21. Burri BJ, Chapman MH, Neidlinger TR, Seo JS, Ishida BK (2009) Tangerine tomatoes increase total and tetra-cis-lycopene isomer concentrations more than red tomatoes in healthy adult humans. Int J Food Sci Nutr 60(1): 1-16.

22. Diwadkar-Navsariwala V, Novotny JA, Gustin DM, Sosman JA, Rodvold KA, et al. (2003) A physiological pharmacokinetic model describing the disposition of lycopene in healthy men. J Lipid Res 44: 1927-1939.

23. Canene-Adams K, Lindshield BL, Wang S, Jeffery EH, Clinton SK, et al. (2007) Combinations of tomato and broccoli enhance antitumor activity in dunning r3327-h prostate adenocarcinomas. Cancer Res 67: 836-843.

24. Limpens J, Schröder FH, de Ridder CM, Bolder CA, Wildhagen MF, et al (2006) Combined lycopene and vitamin $E$ treatment suppresses the growth of PC-346C human prostate cancer cells in nude mice. J Nutr 136: 1287-1293.

25. Yang CM (2011) Growth inhibitory efficacy of lycopene and beta-carotene against androgen-independent prostate tumor cells xenografted in nude mice. Mol Nutr Food Res 55: 606-612.

26. Konijeti R, Henning S, Moro A, Sheikh A, Elashoff D, et al. (2010) Chemoprevention of prostate cancer with lycopene in the TRAMP model. Prostate 70: 1547-1554.

27. Venkateswaran V, Fleshner NE, Sugar LM, Klotz LH (2004) Antioxidants block prostate cancer in lady transgenic mice. Cancer Res 64: 5891-5896.

28. Mucci LA, Tamimi R, Lagiou P, Trichopoulou A, Benetou V, et al. (2001) Are dietary influences on the risk of prostate cancer mediated through the insulinlike growth factor system? BJU Int 87: 814-820.

29. Liu X (2008) Lycopene inhibits IGF--I signal transduction and growth in norma prostate epithelial cells by decreasing DHT-modulated IGF-I production in cocultured reactive stromal cells. Carcinogenesis 29(4): 816-823.

30. Chan JM, Weinberg V, Magbanua MJ, Sosa E, Simko J, et al. (2011) Nutritional supplements, COX-2 and IGF-1 expression in men on active surveillance for prostate cancer. Cancer Causes Control 22: 141-150.

31. Siler U, Herzog A, Spitzer V, Seifert N, Denelavas A, et al. (2005) Lycopene effects on rat normal prostate and prostate tumor tissue. J Nutr 135: 2050S-2S.

32. Talvas J, Caris-Veyrat C, Guy L, Rambeau M, Lyan B, et al. (2010) Differentia effects of lycopene consumed in tomato paste and lycopene in the form of a purified extract on target genes of cancer prostatic cells. Am J Clin Nutr 91: 1716-1724.

33. Qiu X, Yuan Y, Vaishnav A, Tessel MA, Nonn L, et al. (2013) Effects of lycopene on protein expression in human primary prostatic epithelial cells. Cancer Prev Res (Phila) 6: 419-427.

34. Soares Nda C, Teodoro AJ, Oliveira FL, Santos CA, Takiya CM, et al. (2013)
Influence of lycopene on cell viability, cell cycle, and apoptosis of human prostate cancer and benign hyperplastic cells. Nutr Cancer 65: 1076-1085.

35. Teodoro AJ, Oliveira FL, Martins NB, Maia Gde A, Martucci RB, et al. (2012) Effect of lycopene on cell viability and cell cycle progression in human cancer cell lines. Cancer Cell Int 12: 36.

36. Oborna I (2011) A randomized controlled trial of lycopene treatment on soluble receptor for advanced glycation end products in seminal and blood plasma of normospermic men. Am J Reprod Immunol 66: 179-184.

37. Kirsh VA, Mayne ST, Peters U, Chatterjee N, Leitzmann MF, et al. (2006) A prospective study of lycopene and tomato product intake and risk of prostate cancer. Cancer Epidemiol Biomarkers Prev 15: 92-98.

38. Peters U (2007) Serum lycopene, other carotenoids, and prostate cancer risk: a nested case-control study in the prostate, lung, colorectal, and ovarian cancer screening trial. Cancer Epidemiol Biomarkers Prev 16: 962-968.

39. Kristal AR, Till C, Platz EA, Song X, King IB, et al. (2011) Serum lycopene concentration and prostate cancer risk: results from the Prostate Cancer Prevention Trial. Cancer Epidemiol Biomarkers Prev 20: 638-646.

40. Ilic D, Forbes KM, Hassed C (2011) Lycopene for the prevention of prostate cancer. Cochrane Database Syst Rev: CD008007.

41. Bunker $\mathrm{CH}$, McDonald AC, Evans RW, de la Rosa N, Boumosleh JM, et al. (2007) A randomized trial of lycopene supplementation in Tobago men with high prostate cancer risk. Nutr Cancer 57: 130-137.

42. Schröder FH, Roobol MJ, Boevé ER, de Mutsert R, Zuijdgeest-van Leeuwen $\mathrm{SD}$, et al. (2005) Randomized, double-blind, placebo-controlled crossover study in men with prostate cancer and rising PSA: effectiveness of a dietary supplement. Eur Urol 48: 922-930.

43. Barber NJ (2006) Lycopene inhibits DNA synthesis in primary prostate epithelia cells in vitro and its administration is associated with a reduced prostatespecific antigen velocity in a phase II clinical study. Prostate Cancer Prostatic Dis 9: 407-413.

44. Edinger MS, Koff WJ (2006) Effect of the consumption of tomato paste on plasma prostate-specific antigen levels in patients with benign prostate hyperplasia. Braz J Med Biol Res 39: 1115-1119.

45. Bowen P, Chen L, Stacewicz-Sapuntzakis M, Duncan C, Sharifi R, et al. (2002) Tomato sauce supplementation and prostate cancer: lycopene accumulation and modulation of biomarkers of carcinogenesis. Exp Biol Med (Maywood) 227: 886-893.

46. Minutoli L (2014) Inhibitors of apoptosis proteins in experimental benign prostatic hyperplasia: effects of serenoa repens, selenium and lycopene. $J$ Biomed Sci 21:19.

47. Morgia G, Russo GI, Voce S, Palmieri F, Gentile M, et al. (2014) Serenoa repens, lycopene and selenium versus tamsulosin for the treatment of LUTS/ $\mathrm{BPH}$. An Italian multicenter double-blinded randomized study between single or combination therapy (PROCOMB trial). Prostate 74: 1471-1480.

48. Morgia G (2013) Effects of Serenoa repens, selenium and lycopene (Profluss(R)) on chronic inflammation associated with benign prostatic hyperplasia: results of "FLOG" (Flogosis and Profluss in Prostatic and Genital Disease), a multicentre Italian study. Int Braz J Urol 39: 214-221.

49. Morgia G, Mucciardi G, Galì A, Madonia M, Marchese F, et al. (2010) Treatment of chronic prostatitis/chronic pelvic pain syndrome category IIIA with Serenoa repens plus selenium and lycopene (Profluss) versus S. repens alone: an Italian randomized multicenter-controlled study. Urol Int 84: 400-406.

50. Blume-Peytavi U (2009) Cutaneous lycopene and beta-carotene levels measured by resonance Raman spectroscopy: high reliability and sensitivity to oral lactolycopene deprivation and supplementation. Eur J Pharm Biopharm 73: 187-194.

51. Gajendragadkar PR (2014) Effects of oral lycopene supplementation on vascular function in patients with cardiovascular disease and healthy volunteers: a randomised controlled trial. PLoS One 9:e99070. 